\title{
BMJ Open What narrative devices do people with systemic sclerosis use to describe the experience of pain from digital ulcers: a multicentre focus group study at UK scleroderma centres
}

To cite: Jones J, Hughes M, Pauling J, et al. What narrative devices do people with systemic sclerosis use to describe the experience of pain from digital ulcers: a multicentre focus group study at UK scleroderma centres. BMJ Open 2020;10:e037568. doi:10.1136/ bmjopen-2020-037568

- Prepublication history and additional material for this paper are available online. To view these files, please visit the journal online (http://dx.doi org/10.1136/bmjopen-2020037568).

Received 07 February 2020 Revised 11 May 2020 Accepted 18 May 2020
Check for updates

(C) Author(s) (or their employer(s)) 2020. Re-use permitted under CC BY-NC. No commercial re-use. See rights and permissions. Published by BMJ.

For numbered affiliations see end of article.

Correspondence to

Dr Andrew J Moore;

a.j.moore@bristol.ac.uk

\section{ABSTRACT}

Objectives Digital ulcers (DUs) are a common complication in systemic sclerosis (SSc). No existing studies have specifically reported on the qualitative patient experience of DU pain, and our current patientreported outcome measure (PROM) does not capture the multifaceted painful experience of SSc-DU. Our aim was to examine the patient experience of SSc-DU pain.

Design Focus groups with people diagnosed with SSc who had experienced DUs were conducted using a topic guide developed by people with SSc, experts in SSc and experienced qualitative researchers. Focus groups were continued until data saturation had been reached. The focus groups were audio recorded, transcribed verbatim, anonymised and analysed using inductive thematic analysis. Our current study is an integration of the data from these focus groups to specifically examine the patient experience of DU pain.

Setting Three specialist scleroderma units across the UK (Bath, Manchester and London).

Participants Four focus groups were undertaken; 29 adults (20 women, 9 men) with SSc and a spectrum of historical DUs participated. We included participants with a diverse demographic (including ethnic) background and disease-related characteristics.

Results Five narrative devices were identified, which encompass how people describe the pain from SSc-DUs: 'Words to express DU-associated pain', 'Descriptions of physical and psychological reactions to pain', 'Comparisons with other painful events', 'Descriptions of factors that exacerbate pain' and 'Descriptions of strategies for coping with the pain'.

Conclusion The experience of SSc-DU pain leads to the use of graphic language and rich description by participants in the focus group setting. Existing SSc-DU outcomes do not adequately capture the patient experiences of SSc-DU pain. Our findings further highlight the multifaceted nature of SSc-DUs and will hopefully support the development of a novel PROM to assess the severity and impact of SSc-DUs.

\section{INTRODUCTION}

Studies of the lived experience of people with systemic sclerosis ( $\mathrm{SSc}$ ) indicate that pain is
Strengths and limitations of this study

- Two people diagnosed with systemic sclerosisdigital ulcers (SSc-DUs) were involved in the development of the topic guide.

- Focus groups facilitated the discussion of participants to deeply understand the patient experience of SSc-DU pain.

- Findings were discussed with a patient partner with DU disease, which helped to shape the analysis.

- Data from all focus groups were analysed and quotes were selected to be illustrative.

- Sample included only those with a competent level of English language.

one of the most challenging symptoms of this rare autoimmune connective tissue disease. ${ }^{1-3}$ SSc is characterised by widespread vasculopathy, tissue fibrosis and immune system activation. ${ }^{4}$ Around half of people with SSc experience digital ulcers (DUs) at some point in their disease course. ${ }^{5}$ DUs often recur, ${ }^{5-9}$ and the pain from ulcers limit daily activities and impacts on social, family and work life. ${ }^{31011}$ A recent study by Hughes and colleagues found five themes that described patient experience of those with SSC-DUs; 'Disabling pain and hypersensitivity', 'Deep and broad-ranging emotional impact', 'Impairment of physical and social activity', 'Factors aggravating occurrence, duration and impact' and 'Mitigating, managing and adapting'. ${ }^{3}$ Some people with DUs experience such difficult symptoms that they express a desire to have their fingers amputated. ${ }^{13}$ People with SSc-DUs report higher levels of pain than those with SSc without DUs. ${ }^{10} 1213$

Pain has been described as 'always subjective ${ }^{, 14}$; the problem of pain and its subjectivity is compounded by a lack of consideration of 
the first person perspective in guidelines on how to assess pain. ${ }^{15} 16$ For example, the McGill Pain Questionnaire (MPQ), a multidimensional scaling device for assessing pain, includes three measures; a pain rating index, a count of pain descriptors used and present pain intensity, ${ }^{17}$ but like most measures it lacks provision for capturing the lived experience of pain. Previous qualitative work has alluded to the pain associated with DUs. ${ }^{18} 19$ However, we have limited information on the lived experience of those with SSc-DUs and how people express specific aspects of their pain. ${ }^{11}$ Previous qualitative research in other diagnoses has investigated more deeply how pain is experienced and expressed and how it interferes with one's life. ${ }^{20-34}$ One of the problems inherent in how we respond clinically to pain is that when pain is assessed it is often measured, with a focus on pain intensity using quantitative scales. ${ }^{23}$ However, there is an indication that patients use different approaches when rating pain intensity on scales such as the Brief Pain Inventory (BPI), which includes considering how pain fluctuates as well as the location and duration of the pain. ${ }^{20}$ The study by Dannecker $e t a l^{20}$ also found that activity items measured on the Western Ontario and MacMaster Osteoarthritis Index (WOMAC) helped provide context for patients to remember pain experience.

The Multimodal Assessment Model of Pain (MAP) distinguishes between qualitative (words and behaviours) and quantitative (self and non-self-reported measures) assessments of pain and regards the qualitative pain narrative as the best available root proxy for inferring pain in others' ${ }^{35}$ Wideman et al describe 'pain expression' as the broad collection of qualitative words and behaviours that communicate pain'. They divide pain expression into two components: 'pain narrative', comprising words used to describe pain; and 'pain behaviour', which comprises nonverbal and para-verbal pain-related behaviours. ${ }^{35}$ Bostick $e t a l^{36}$ found that the 'pain narrative' is important for capturing the experience of women who live with chronic pain conditions and suggest that it should be included alongside quantitative pain assessment measures. Pain is an important symptom of many health conditions, and some conditions have bespoke measurement scales to capture the severity and impact of pain such as WOMAC for osteoarthritis pain. ${ }^{37}$

The aim of the present study was to explore the nature of pain related to SSc-DUs using data obtained from a multicentre qualitative research study examining the patient experience of SSc-DUs, which had identified pain as a key and central focus defining the patient experience. ${ }^{3}$ The specific objectives of this analysis were to first capture 'pain expression' and the pain narrative of people with SSc-DUs and second, to understand how the language and expressions relating to DUs could inform the narrative of clinical consultations.

\section{METHODS}

Four focus groups (FGs) were conducted. Participants were recruited from three UK SSc specialist centres who care for patients with DU complications. The FG topic guide was developed by the steering committee that included people diagnosed with SSc with a history of DUs (online supplementary appendix 1). In brief, FGs were chosen for data collection because they allow interaction between participants and the opportunity for any new topics to be discussed that may not have emerged in 1:1 interview settings. FGs continued until thematic saturation had been reached. Participants were adults aged over 18 (range 33-87) years with sufficient English language skills to be able to take part in an FG. Potential participants were identified at routine clinic assessment or through a database of patients who had given prior consent to be considered for future research studies. FGs were held in informal settings away from the clinical areas and were all facilitated by MH (a consultant rheumatologist with special interest in SSc), sometimes in conjunction with another consultant rheumatologist and SSc specialist (JP) and a qualitative researcher (AJM) from the project team. ${ }^{3}$ FGs continued until thematic saturation had been reached, such that no new codes or themes were developing by the fourth FG. ${ }^{38}$ We used the Standards for Reporting Qualitative Data (SRQR) checklist when writing our report. ${ }^{39}$

Thematic analysis of the transcripts was conducted by JJ and AJM (both experienced qualitative researchers) with further input from the wider team including $\mathrm{MH}, \mathrm{JP}$ and RG-H and patient partners. ${ }^{40}$ The data were imported into NVivo V.11 software to manage and facilitate its interrogation. Our approach was both deductive and inductive. Deductive in the sense that the research team examined preconceived considerations of the impact of DUs and how they were understood and managed based on an earlier comprehensive literature review. ${ }^{11}$ The approach was inductive in that there was no pre-existing coding frame and the developing codes were derived from and grounded in the data. ${ }^{41}$ Previously reported findings from this study included the range and nature of the impact of SSC-DUs on hand functionality, social functioning, psychological impacts and pain. ${ }^{3}$ As pain was a major element, we felt that a more in-depth exploration was warranted. This analysis explores the theme of pain in greater depth, for the purposes of developing a future patient-reported outcome measure (PROM), and to inform discussions about pain between healthcare practitioners and people diagnosed with SSc experiencing DUs.

\section{Patient and public involvement}

People diagnosed with SSc with a history of DUs helped develop the topic guide as part of the steering committee and also contributed to the analysis process by commenting on the first thematic analysis outputs.

\section{RESULTS}

The study cohort comprised 29 patients with SSc and either a history of DUs or current DUs. A summary of the 
Table 1 Demographics and clinical phenotype of enrolled participants (adapted with permission from Hughes et al ${ }^{3}$ )

\begin{tabular}{|c|c|c|c|c|c|}
\hline Demographics/clinical phenotype & Bath & Manchester & London (1) & London (2) & Overall \\
\hline Number of participants, $n$ & 8 & 7 & 6 & 8 & 29 \\
\hline Mean age in years, (range) & $66.1(44.0-87.6)$ & $61.6(41.9-73.3)$ & $50.4(33.7-67.7)$ & $59.5(36.7-72.7)$ & $59.9(33.7-87.6)$ \\
\hline \multicolumn{6}{|l|}{ Disease subtype, $\mathrm{n}$} \\
\hline LcSSc & 8 & 6 & 2 & 4 & 20 \\
\hline Mean disease duration* in years (range) & $14.3(3.3-33.3)$ & $10.9(1.7-23.8)$ & $13.9(1.7-37.7)$ & $13.2(4.7-31.7)$ & $12.8(1.7-37.7)$ \\
\hline \multicolumn{6}{|l|}{ Early vs established disease $\dagger, \mathrm{n}$} \\
\hline Early & 0 & 1 & 1 & 0 & 2 \\
\hline Established & 8 & 6 & 5 & 8 & 27 \\
\hline
\end{tabular}

History of DU, $\mathrm{n}$

\begin{tabular}{|c|c|c|c|c|c|}
\hline 1 previous DU & 1 & 1 & 0 & 1 & 3 \\
\hline 2-4 previous DU & 3 & 3 & 2 & 1 & 9 \\
\hline$\geq 5$ previous $\mathrm{DU}$ & 4 & 3 & 4 & 6 & 17 \\
\hline White/Caucasian & 7 & 6 & 5 & 5 & 23 \\
\hline Black British & 0 & 1 & 1 & 2 & 4 \\
\hline None & 1 & 2 & 1 & 2 & 6 \\
\hline Calcium channel blocker & 5 & 2 & 1 & 2 & 10 \\
\hline Phosphodiesterase type-5 inhibitor & 5 & 4 & 4 & 5 & 18 \\
\hline Endothelin receptor antagonist & 3 & 2 & 2 & 2 & 9 \\
\hline
\end{tabular}

*Since first non-Raynaud's symptom.

$\dagger$ Early and established disease (defined as $\leq 3$ and $>3$ years since first non-Raynaud's phenomenon symptom, respectively). łIndication not specified and includes SSc-RP, SSc-DU, SSc-pulmonary artery hypertension and/or systemic hypertension/cardiovascular risk. DcSSc, diffuse cutaneous systemic sclerosis; DU, digital ulcer; LcSSc, limited cutaneous systemic sclerosis ${ }^{55}$; RP, Raynaud's phenomenon.

main patient characteristics is presented in table 1 and has been described previously. ${ }^{3}$

Participants in the FGs talked about pain using a variety of descriptive tools such as metaphor, simile, adjectives and graphic description (see figure 1). The participants

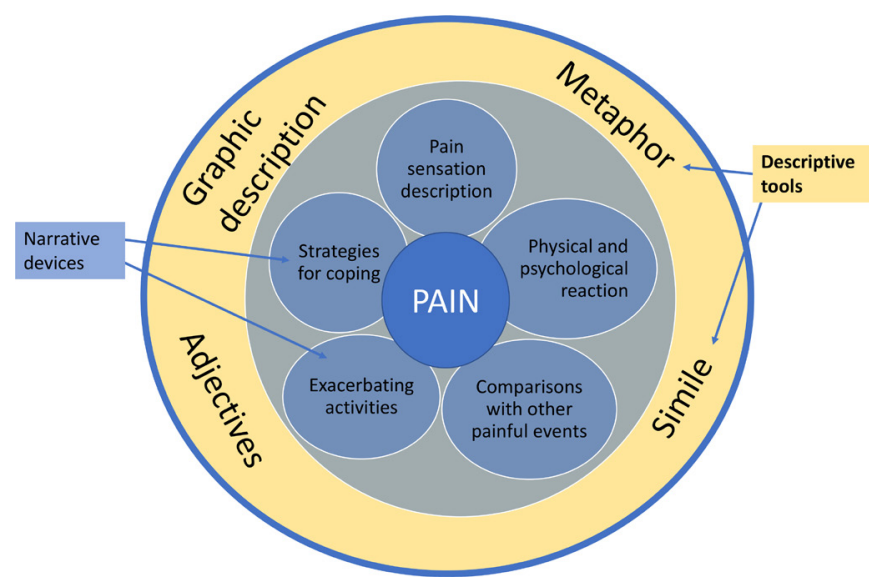

Figure 1 Pain experience: narrative devices and descriptive tools. were found to use these descriptive tools to talk about pain in different ways, which we have called 'narrative devices'. The narrative devices all served the purpose of underlining how severe the pain was and how that was articulated by individuals.

Five narrative devices were identified, which will be expanded on below:

- Words to express DU-associated pain.

- Descriptions of physical and psychological reactions to pain.

- Comparisons with other painful events.

- Description of factors that exacerbate pain.

- Descriptions of strategies for coping with the pain.

\section{Words to express DU-associated pain}

Participants used a variety of words to describe the quality of pain associated with their DUs including soreness, tenderness or discomfort. Often words used to describe the intensity of pain were extreme (table 2).

One participant suggested the words that would best describe pain were all four letter words', implying that profanity reflected perhaps a mixture of emotions 
Table 2 Words to describe intensity and nature of digital ulcer pain

\begin{tabular}{lllll}
\hline 'unbelievable' & 'agonising' & 'really hurt' & 'throb' & 'constant pain' \\
'stabbing feeling' & 'absolutely horrible' & 'properly painful' & 'absolutely agony' & 'pulsating pain' \\
'unbearable' & 'severe' & 'stingy' & 'agony' & 'intense pain' \\
\hline
\end{tabular}

including severity and frustration (FG1, participant (par) 7). There was acknowledgement among the participants that the amount of pain experienced was often disproportionate to the size of the ulcer that was causing the pain.

it's quite incongruous the amount of pain from the minimal amount of disruption to your thumb (FG2, par5)

The location of the pain was usually mentioned only if it was beyond the ulcer itself; for example, the pain was described as sometimes appearing in adjacent fingers that were ulcer free or described as shooting up the arm. One participant described how the pain seemed to hurt their whole body if the ulcer was touched.

Participants described great variation in how long the pain from their ulcer lasted with one participant saying they were in pain for half an hour after knocking their ulcer while another described how pain was severe for 3 to 4 days after an ulcer emerged. Some participants commented on the build-up of a painful internal pressure in the area where an ulcer was about to emerge.

I feel mine before I see them, I can feel that pain. (FG3, par4)

With me, it was a build-up of pressure on my index finger, the actual pad itself, (FG1, par2)

\section{Descriptions of physical and psychological reactions to pain}

Some participants described how they reacted to the pain, for example, wanting to cry, roll around on the floor or rock backwards and forwards. One participant spoke of wanting to defer the pain to another part of the body.

When the pain is really bad you, you just rock back and forward like this (FG1, par8)

You feel like you want to bang your head to refer the pain somewhere else, just to relieve it (FG2, par6)

The pain, I just wanted to sit on the floor and cry ... the pain is the worst thing I've had (FG2, par1)

They're painful if I knock them, I'm on the floor rolling (FG3, par2)

Participants also described how they reacted psychologically to the pain, expressing feelings of anger, fear, frustration and depression. The state of constant vigilance employed by some participants added to the psychological burden they experienced.

Just angry all the time because you have to be conscious and you can't relax... And it affects you, yes, it affects you and it affects the kids, it affects everything around you. You have to tell yourself all the time, you've got this, you have to, you have to remember your hand all the time (FG2, par7)

\section{Comparisons with other painful events}

Some respondents compared the pain of an SSc-DU to other experiences or imagined scenarios. Box 1 summarises a range of similes used (all the respondents used the phrase 'like' or 'as if'). One respondent started with a volcano metaphor that then turned into a simile:

You know it's going to erupt into a volcano, and it starts all rough and there's a point where it hurts a lot and it just keep on coming out. It does feel like a volcano in a weird way. It starts from here and it starts pushing out and it's that you can't stop it, it keep's coming, coming... getting bigger like this, but inside the finger tip. (FG4, par7)

In trying to convey how unbearable the pain was, more than one participant indicated the extreme scenario of wanting to cut the finger open or to have part of the finger or the nail amputated/removed to relieve the pain.

it's just so painful that the idea of cutting my finger open to take it out seems better than having that pain all the time. (FG2, par7)

\section{Box 1 Digital ulcer pain similes}

'To me it's a bit like when you're a child and you fall over and graze your knee and it's open but the, the, you just don't see anything there, there's a slight redness but it almost feels as if you've taken the skin off with a cheese grater and it's exposed'. (FG1, par4)

'I find the smaller one are like rose thorns stuck in your finger that you can't get out and, it's like three kinds of pain really, another one is where I feel as though l've scalded me finger and then another one is like I just slammed the car door on it'. (FG2, par6)

'For me, this finger here it's as if somebody's got a needle, a very fine needle and they've just slipped it in and they're just wiggling it, like there, sometimes I sit there and I search to see is there a needle in there?' (FG3, par4)

'It feels like your finger, someone's closed the door on your finger and they're holding the door tight and your finger is in the hinge of the door' (FG4, par8)

'Like someone's getting a nail and hammering a nail right through the tip .... And keep going and going, because it just keeps going through the finger' (FG4, par7)

'It's like somebody's sticking a needle in your finger when you're trying to go to sleep, you hold your hand up in the air' (FG2, par1) 


\section{Description of factors that exacerbate pain}

Participants described a variety of ways in which the ulcer could cause pain and how some of their activities were limited as a consequence, thus impacting on their social, family and working lives. The main cause of pain was any direct contact with the ulcer such as knocking or catching the ulcer on something. Sometimes the contact did not have to be very strong; one participant described holding a newspaper as being painful. Another participant found that if the ulcer became infected it was more painful and therefore they avoided situations where the risk of infection was higher.

I try not to get mine infected because then the pain level goes up...even just going and brushing our teeth it's painful when our hands are sore and ulcerated. (FG3, par5)

A change of air or water temperature also triggered pain. Some participants described the cold air-conditioned section of supermarkets as being painful. Participants also had to avoid direct contact with cold objects, such as foods in the freezer or fridge, as it could be painful even after ulcers had healed. Having a protective dressing on the ulcer was not enough to prevent pain when the area was touched or in changing temperatures.

When you put it in hot water or cold water, moving from one room to another it would just set the pain off again. (FG1, par2)

Participants accepted that pain would occur when ulcers were present. Most participants described knocking or catching their DU on objects leading to extreme pain, despite their best attempts at protecting the DU to prevent contact. This could impact on social interaction, such as difficulty avoiding shaking hands, despite knowledge that this could be very painful for them. Another participant observed that having young children meant some activities could not be avoided and so endured pain to enable her to fulfil their parental role.

\section{Description of strategies for coping with the pain}

Pain caused by the ulcer determined the extent to which people could or could not participate in daily activities. For some, this meant social isolation and reduced work participation. Some continued working in the same job without taking time off but tried to avoid knocking their ulcers; whereas others had to change role within the organisation, while some had either changed their job or stopped working completely. For some participants, it was not solely the pain from their ulcers, which had led to occupational changes but also the impact of other SSc issues such as reduced hand mobility.

Participants described several different methods of coping with the pain. The main method was avoiding situations where the ulcer could get knocked or exposure to temperature changes, or risk of infection, or activities such as gardening or cooking where the hands could potentially be damaged or exposed to irritants (such as

\section{Box 2 Coping strategies for digital ulcers}

'Well I've got this thing for my seat belt which is invaluable'. (FG2, par 6) 'I wear gloves all the time, in fact I even wear gloves in bed because it keeps your hands warm and that does help me, in fact it helps the ulcers because your hands are warm'. (FG4, par 1)

'I've got things that help me grip jars' (FG3, par 4)

'I keep a pair of gloves up on top of the fridge freezer to do just that, you know, to take anything out from the freezer'. (FG1, par 8)

'Avoid cold weather... Rethinking strategies and things like that... I have disposable gloves at home for doing things 'cause l've often got dressings on, so I can't wash my hands after cooking or something so I wear rubber gloves to do things'. (FG3, par 2)

'One good thing is if you wear gloves people are sort of won't touch your hands, like if they shake hands, if you have gloves on all the time, they sort of think if you're wearing gloves there must be something wrong with you so they won't put their hand out'. (FG4, par1)

'They are changing the way supermarket trolleys are now, but I used to carry pliers around with me to get my pound coin' (FG2, par 6)

'I've got little pieces of blue tack around the place so that if things get dropped then I just tap it with a big of blue tack and then I know l've got'. (FG1, par 1)

'The other thing l've tried to make is a stand-off dressing. You know you get the thing you put on your finger to put your bandage on, I've used one of those and taped it to the finger to create an extension... So that I've got something hard, but trying to find something off the shelf that's purpose made for that, I couldn't find anything so I used to try and make my own up, but obviously your finger was then stiff, because it was like having a splint on'. (FG1, par7)

infection). Many gave examples of activities they could still do in their family, social or work life but also admitted that there were some activities that they had given up either temporarily or permanently. This was often with much regret, but they felt they were controlling the ulcers by doing so.

I find when you're trying to wash up or anything as well, you know the washing up liquid and stuff like that, you're frightened of even getting that on your hands when you've got an ulcer... 'Cause I have touched on the odd occasion, you've just touched something that you use every day and you think, oh, has that made it worse? (FG2, par1)

As well as receiving support from friends and family, participants also used adaptive devices to help avoid painful situations-some of these were bought, while others were home-made. Participants mentioned tools that helped to open jars and bottles and one participant mentioned having a device that helped with putting on the seat belt otherwise they would have found driving extremely challenging. The most commonly mentioned 'device' was gloves that were used to protect the hands (from knocks and temperature changes). Gloves had the added advantage that in social situations others may avoid shaking hands if they suspected that something was wrong with the gloved hands. See box 2 for coping strategies.

Supermarkets in particular seemed to be a location where participants either avoided or adapted to their 
situation. One participant said she used a pair of pliers to remove the token from the trolley at the supermarket. Several mentioned that they simply gave the cashier their purse for them to get the money out as it was too painful for them to do so themselves. Home-made devices were often those that helped participants pick up small objects as the ulcer restricted their ability to perform pinching movements in the hand as well as being painful. A few participants also described wound dressings that they had devised, which helped protect the ulcer.

\section{DISCUSSION}

To our knowledge, ours is the first study to comprehensively explore qualitatively the patient experience of SSc-DU pain. The key finding of our study is that people with SSc-DUs express their pain in multiple ways using a rich variety of descriptive tools. We have identified five narrative devices: describing pain sensations; describing the physical and psychological reaction to the pain; comparisons with other painful events or imagined extreme solutions to unbearable pain; descriptions of factors that exacerbate pain and limits participation in the world; and describing the strategies for coping with the pain. These narrative devices resonate with the lived experience of pain described by people with SSc, ${ }^{11}$ Raynaud's phenomenon ${ }^{42}{ }^{43}$ and other conditions (eg, osteoarthritis, ${ }^{20}$ pancreatic cancer, ${ }^{21}$ dysmenorrhoea, ${ }^{44}$ necrotising fasciitis, ${ }^{45}$ acute intermittent porphyria ${ }^{22}$ ).

The participants' pain narratives exhibit a diverse use of language; both elements of Wideman's ${ }^{35}$ pain expression (pain narrative and pain behaviour) are evident in the transcripts. Rather than being observed, "pain behaviour' was described by participants (such as rocking backwards and forwards). This has not been noted in SSc studies before ${ }^{11}$ but has been observed in studies of other conditions describing pain (ie, fall to the floor, curl up in a ball, curl up in the fetal position and cry). ${ }^{44647}$ Psychological reactions to pain (anger, fear, frustration, depression) were also described in our study as well as previous studies as people talked about how pain overwhelmed or frightened them or negatively impacted their mood, leaving them frustrated, aggravated, depressed or hypervigilant. ${ }^{25-28}$ This suggests that people are able to convey how they physically and psychologically react to pain without the need for an independent observer to be present in the moment pain is being experienced.

Many studies (including one on Raynaud's phenomenon $^{42}$ ) have described the language and descriptions used to convey the pain experience of participants in terms of the type of pain experienced (ie, grinding, cramping, stabbing, burning) ${ }^{20-22} 42$ and the intensity of the pain (ie, excruciating, unbearable, worst pain in the world, cannot be controlled by pain medication). Many but not all of these terms used by people in these studies can be found in the MPQ. ${ }^{17}$ In our study, those with SSc-DUs used descriptive tools that were beyond the original MPQ list of words, suggesting that single words or adjectives cannot fully convey the lived experience of pain. In studies of other conditions, pain intensity could also be described by what relieved the pain in terms of medication ${ }^{23}$ or in other cases how medication was not able to alleviate the pain. ${ }^{15}$ The participants in the SScDUs FGs did not tend to describe their pain in terms of relief through pain medication but instead described strategies they used for coping with the pain while some indicated the extreme scenario of wanting the finger to be amputated/removed to relieve the pain; a similar finding was described by Suarez-Almazor and colleagues ${ }^{1}$ when investigating SSc.

Various studies, including those on SSc, have shown that people employ graphic descriptions to convey their experience of pain, making use of analogy, simile and metaphor. These make pain more visual and visceral to the listener. ${ }^{1}{ }^{15}$ 22-26 28-30 4445 48-51 Participants in our FGs used strong imagery to describe their pain to others in the group; they did not tend to say that they were lost for words to describe their pain. We believe that the willingness to use such imagery to describe pain was in part because FGs enabled all participants to share their pain narrative. It seems likely that if a clinical consultation similarly enabled participants to describe their pain, then they would also provide detailed descriptions of their pain, including simile and other figures of speech.

The patient experience of SSc-DU has a significant impact on people's ability to function. ${ }^{11}$ In our study, ulcer pain was described to limit functionality (social, domestic and work related) within the participant group. The FG participants described many ways in which they avoided potential painful situations or used aids/devices to help with their day to day living; similar to how people with other painful conditions have described strategies for dealing with their pain. ${ }^{1528}$ To understand the lived experience of pain better, it is necessary to capture how people employ strategies to live with the pain; this knowledge may help in developing pain management strategies.

People with SSc-DUs talk about pain in many different ways. Single, unidimensional scales such as Visual Analogue Scales (VAS) that only assess the intensity of the pain experienced exclude the multifaceted nature of DU pain. Multidimensional scales can potentially address this but are still limited in their ability to capture the context and lived experience of pain. People need to express their pain, otherwise there is the risk that they become isolated in their pain, ${ }^{47}$ especially if scars have healed and there is the expectation that there should no longer be pain. This is especially pertinent for those with SSc-DUs as participants talked about pain from 'healed' ulcers as well as active ulcers. ${ }^{52}$

Describing their extreme pain using graphic language seemed to come quite easily to the participants in the FG setting. However, hearing these pain narratives in a clinical environment may be challenging for some healthcare professionals who need the understanding, the will and the humanity to hear beyond the words and see behind the picture'. ${ }^{48}$ As Pither ${ }^{53}$ says 'Listening and 
acknowledgement are fundamental'. The need to be believed by both friends and family and especially healthcare professionals came through strongly in studies of other conditions with the recommendation that pain is perhaps better captured as a dialogue between HCP and patient rather than by the standardized rating scales alone ${ }^{15}$ Our study adds to the wealth of studies, which recommend listening to the patient narrative alongside capturing a mark on a pain scale. ${ }^{151654}$ The extreme pain experienced and the specific effect of certain activities on those with DUs highlight the potential value of a specific PROM for DUs that fully captures how patients 'feel' and 'function'. Pain would likely be a central feature. Such a PROM would need to capture the extreme nature of the pain, its duration, when pain happens and what activities are avoided due to the fear of pain.

\section{CONCLUSION}

It is possible there are other descriptive tools that people with SSc-DUs use to describe their pain experience that was not captured in this study. Data were collected from 29 participants across four FGs who were all able to converse in English, so we have no information on how those who express themselves in other languages may speak about pain. Participants in this study were predominantly women. This is a weakness, and further research could ensure that more men are included, this is particularly advisable given that previous research has shown gender differences in pain language. ${ }^{2454}$

This study was based on FGs that were designed to understand the patient experience of SSc-DUs including to inform the development of a new PROM for adults with DUs. Pain was not the only element of their experience that was elicited; however, we found that it was a major one. Participants were able to speak freely during the FGs about their DU experiences and a novel, rich data set has been collected and robustly analysed.

Patients' experiences of SSc-DU pain are multidimensional; and understanding the complexity of SSc-DU pain may support the clinical assessment and the development of novel ulcer outcome measures. These could assess different elements of pain: nature and intensity, physical and psychological reaction; comparing with other known pain events; how pain limits functionality and how pain is managed. Alongside this, it could be valuable for future PROMS to include items that elicit and record 'pain expression' qualitatively, ${ }^{36}$ potentially including descriptions of 'pain behaviours', as well as the impact of pain on mood.

Furthermore, in clinical practice, decision-making might be enhanced when patients are enabled to speak about their pain in narrative form. Clinicians enabling and acknowledging patients' lived experience of pain may help to legitimise the patient's pain, thereby removing a number of potential barriers to shared decision-making about ulcer pain management. Furthermore, greater understanding of how those with SSc experience DU pain could help to inform the development of novel approaches to the treatment of SSc-DUs.

\section{Author affiliations}

${ }^{1}$ Health Sciences, University of Leicester, Leicester, UK

${ }^{2}$ Musculoskeletal Research Unit, Translational Health Sciences, Bristol Medical School, University of Bristol, Bristol, UK

${ }^{3}$ Centre for Musculoskeletal Research, Faculty of Biology, Medicine and Health, University of Manchester, Manchester, UK

${ }^{4}$ Department of Rheumatology, Royal Hallamshire Hospital, Sheffield Teaching Hospitals NHS Foundation Trust, Sheffield, UK

${ }^{5}$ Department Pharmacy and Pharmacology, University of Bath, Bath, UK ${ }^{6}$ Rheumatology Department, Royal National Hospital For Rheumatic Diseases NHS Foundation Trust, Bath, UK

${ }^{7}$ NIHR Bristol Biomedical Research Centre, University Hospitals Bristol NHS Foundation Trust, Bristol, UK

Acknowledgements The authors would like to acknowledge the contributions of the steering committee: Christopher P Denton, Robyn T Domsic, Tracy M Frech, Ariane L Herrick, Dinesh Khanna, Marco Matucci-Cerinic and Lesley Ann Sakettkoo and two patient research partners; Lorraine McKenzie and Jane Withey. The authors also acknowledge the focus group participants for their time and sharing their stories and experiences.

Contributors MH, JP, RG-H and AJM were on the steering committee that designed the study and developed the topic guide. MH undertook the focus groups. JP and AJM observed one of the focus groups. JJ and AJM initially analysed the data, all authors discussed the analysis and contributed towards the ongoing analysis of the dataset. JJ wrote the first draft of the paper, all authors commented and edited drafts of the paper.

Funding This work was supported by the Scleroderma Clinical Trials Consortium.

Competing interests JP reports personal fees from Boehringer Ingelheim; grants, personal fees and non-financial support from Actelion Pharmaceuticals and personal fees from Sojournix Pharma, outside the submitted work. MH has received speaker honoraria (<US\$10 000) from Actelion Pharmaceuticals. JJ, RG-H and AJM do not report any competing interests relevant to the content of this work.

Patient and public involvement Patients and/or the public were involved in the design, or conduct, or reporting, or dissemination plans of this research. Refer to the Methods section for further details.

\section{Patient consent for publication Not required.}

Ethics approval Ethical approval was provided by the East Midlands-Nottingham 1 research Ethics Committee (REC reference-18/EM/0018) and all participants provided informed written consent before taking part.

Provenance and peer review Not commissioned; externally peer reviewed.

Data availability statement Anonymised qualitative data from this study are available on reasonable request. Please contact michael.hughes-6@manchester.ac. uk in the first instance.

Open access This is an open access article distributed in accordance with the Creative Commons Attribution Non Commercial (CC BY-NC 4.0) license, which permits others to distribute, remix, adapt, build upon this work non-commercially, and license their derivative works on different terms, provided the original work is properly cited, appropriate credit is given, any changes made indicated, and the use is non-commercial. See: http://creativecommons.org/licenses/by-nc/4.0/.

\section{ORCID iDs}

Jennifer Jones http://orcid.org/0000-0001-6936-6092

Andrew J Moore http://orcid.org/0000-0003-3185-1599

\section{REFERENCES}

1 Suarez-Almazor ME, Kallen MA, Roundtree AK, et al. Disease and symptom burden in systemic sclerosis: a patient perspective. $J$ Rheumatol 2007;34:1718-26.

2 Denton CP, Khanna D. Systemic sclerosis. Lancet 2017;390:1685-99.

3 Hughes M, Pauling JD, Jones J, et al. Multicenter qualitative study exploring the patient experience of digital ulcers in systemic sclerosis. Arthritis Care Res 2020;72:723-33. 
4 Hughes M, Herrick AL. Systemic sclerosis. Br J Hosp Med 2019;80:530-6.

5 Hughes M, Herrick AL. Digital ulcers in systemic sclerosis. Rheumatology 2017;56:14-25.

6 Hachulla E, Clerson P, Launay D, et al. Natural history of ischemic digital ulcers in systemic sclerosis: single-center retrospective longitudinal study. J Rheumatol 2007;34:2423-30.

7 Steen V, Denton CP, Pope JE, et al. Digital ulcers: overt vascular disease in systemic sclerosis. Rheumatology 2009;48 Suppl 3:iii19-24.

8 Tiev KP, Diot E, Clerson P, et al. Clinical features of scleroderma patients with or without prior or current ischemic digital ulcers: post-hoc analysis of a nationwide multicenter cohort (ItinérAIRSclérodermie). J Rheumatol 2009;36:1470-6.

9 Khimdas S, Harding S, Bonner A, et al. Associations with digital ulcers in a large cohort of systemic sclerosis: results from the Canadian scleroderma Research Group registry. Arthritis Care Res 2011;63:142-9.

10 Mouthon L, Carpentier PH, Lok C, et al. Ischemic digital ulcers affect hand disability and pain in systemic sclerosis. $J$ Rheumatol 2014;41:1317-23.

11 Hughes M, Pauling JD. Exploring the patient experience of digital ulcers in systemic sclerosis. Semin Arthritis Rheum 2019;48:888-94.

12 Mouthon L, Mestre-Stanislas C, Bérezné A, et al. Impact of digital ulcers on disability and health-related quality of life in systemic sclerosis. Ann Rheum Dis 2010;69:214-7.

13 Bérezné A, Seror R, Morell-Dubois S, et al. Impact of systemic sclerosis on occupational and professional activity with attention to patients with digital ulcers. Arthritis Care Res 2011;63:277-85.

14 International Association for the Study of Pain. IASP terminology, 2018. Available: https://www.iasp-pain.org/terminology? navltemNumber $=576$

15 Coleman B, Ellis-Caird H, McGowan J, et al. How sickle cell disease patients experience, understand and explain their pain: an interpretative phenomenological analysis study. Br J Health Psychol 2016;21:190-203.

16 Eriksson K, Wikström L, Fridlund B, et al. Patients' experiences and actions when describing pain after surgery--a critical incident technique analysis. Int J Nurs Stud 2016;56:27-36.

17 Melzack R. The McGill pain questionnaire: major properties and scoring methods. Pain 1975;1:277-99.

18 Stamm TA, Mattsson M, Mihai C, et al. Concepts of functioning and health important to people with systemic sclerosis: a qualitative study in four European countries. Ann Rheum Dis 2011;70:1074-9.

19 Kocher A, Adler S, Spichiger E. Skin and mucosa care in systemic sclerosis--patients' and family caregivers' experiences and expectations of a specific education programme: a qualitative study. Musculoskeletal Care 2013;11:168-78.

20 Dannecker EA, Warne-Griggs MD, Royse LA, et al. Listening to patients' voices: Workarounds patients use to construct pain intensity ratings. Qual Health Res 2019;29:484-97.

21 Tang C-C, Draucker C, Tejani M, et al. Symptom experiences in patients with advanced pancreatic cancer as reported during healthcare encounters. Eur J Cancer Care 2018;27:e12838.

22 Simon A, Pompilus F, Querbes W, et al. Patient perspective on acute intermittent porphyria with frequent attacks: a disease with intermittent and chronic manifestations. Patient 2018;11:527-37.

23 Bergh I, Jakobsson E, Sjöström B, et al. Ways of talking about experiences of pain among older patients following orthopaedic surgery. J Adv Nurs 2005;52:351-9.

24 Gooberman-Hill R, French M, Dieppe P, et al. Expressing pain and fatigue: a new method of analysis to explore differences in osteoarthritis experience. Arthritis Rheum 2009;61:353-60.

25 Lee AL, Harrison SL, Goldstein RS, et al. An exploration of pain experiences and their meaning in people with chronic obstructive pulmonary disease. Physiother Theory Pract 2018;34:765-72.

26 Paulson M, Danielson E, Larsson K, et al. Men's descriptions of their experience of nonmalignant pain of fibromyalgia type. Scand $J$ Caring Sci 2001;15:54-9.

27 Closs SJ, Briggs M. Patients' verbal descriptions of pain and discomfort following orthopaedic surgery. Int J Nurs Stud 2002;39:563-72.

28 Hallberg LR, Carlsson SG. Coping with fibromyalgia. A qualitative study. Scand J Caring Sci 2000;14:29-36.
29 Duggleby W. The language of pain at the end of life. Pain Manag Nurs 2002:3:154-60.

30 Zalon ML. Pain in frail, elderly women after surgery. Image $J$ Nurs Sch 1997;29:21-6.

31 Good BJ, Good MD, Brodwin PE, et al. Pain as human experience: an anthropological perspective. US: Berkeley University of California Press, 1992.

32 Scarry E. The body in pain: the making and Unmaking of the world. New York: Oxford University Press, 1985.

33 Morris DB. The culture of pain. US: University of California Press, 1991.

34 Sullivan MD. Pain in language - from sentience to sapience. Pain Forum 1995;4:3-14.

35 Wideman TH, Edwards RR, Walton DM, et al. The multimodal assessment model of pain: a novel framework for further integrating the subjective pain experience within research and practice. Clin J Pain 2019;35:212-21.

36 Bostick GP, Dick BD, Wood M, et al. Pain assessment recommendations for women, made by women: a mixed methods study. Pain Med 2018;19:1147-55.

37 Breivik H, Borchgrevink PC, Allen SM, et al. Assessment of pain. $\mathrm{Br} \mathrm{J}$ Anaesth 2008:101:17-24.

38 Saunders B, Sim J, Kingstone T, et al. Saturation in qualitative research: exploring its conceptualization and operationalization. Qual Quant 2018;52:1893-907.

39 O'Brien BC, Harris IB, Beckman TJ, et al. Standards for reporting qualitative research: a synthesis of recommendations. Acad Med 2014;89:1245-51.

40 Braun V, Clarke V. Using thematic analysis in psychology. Qual Res Psychol 2006;3:77-101.

41 Glaser B, Strauss A. The discovery of Grounded theory: strategies for qualitative research. Chicago: Aldine, 1967.

42 Pauling JD, Domsic RT, Saketkoo LA, et al. Multinational qualitative research study exploring the patient experience of Raynaud's phenomenon in systemic sclerosis. Arthritis Care Res 2018;70:1373-84.

43 Pauling JD, Frech TM, Hughes M, et al. Patient-Reported outcome instruments for assessing Raynaud's phenomenon in systemic sclerosis: a SCTC vascular Working Group report. J Scleroderma Relat Disord 2018;3:249-52.

44 Chen CX, Draucker CB, Carpenter JS. What women say about their dysmenorrhea: a qualitative thematic analysis. BMC Womens Health 2018;18:47.

45 Erichsen Andersson A, Egerod I, Knudsen VE, et al. Signs, symptoms and diagnosis of necrotizing fasciitis experienced by survivors and family: a qualitative Nordic multi-center study. BMC Infect Dis 2018;18:429.

46 El-Haddad C, Damodaran A, Patrick McNeil H, et al. The experience of patients admitted to hospital with acute low back pain: a qualitative study. Int $J$ Rheum Dis 2018;21:796-803.

47 Kugelmann R. Complaining about chronic pain. Soc Sci Med 1999;49:1663-76.

48 Schott GD. Communicating the experience of pain: the role of analogy. Pain 2004;108:209-12.

49 Hearn JH, Finlay KA, Fine PA. The devil in the corner: a mixedmethods study of metaphor use by those with spinal cord injuryspecific neuropathic pain. Br J Health Psychol 2016;21:973-88.

50 Wilson O, Kirwan J, Dures E, et al. The experience of foot problems and decisions to access foot care in patients with rheumatoid arthritis: a qualitative study. J Foot Ankle Res 2017;10:4

51 Jairath N. Myocardial infarction patients' use of metaphors to share meaning and communicate underlying frames of experience. $J \mathrm{Adv}$ Nurs 1999;29:283-9.

52 Hughes M, Pauling JD, Jones J, et al. Patient experiences of digital ulcer development and evolution in systemic sclerosis. Rheumatology; 75 .

53 Pither C. Finding a visual language for pain. Clin Med 2002;2:570-1.

54 Jaworska S, Ryan K. Gender and the language of pain in chronic and terminal illness: a corpus-based discourse analysis of patients' narratives. Soc Sci Med 2018;215:107-14.

55 LeRoy EC, Black C, Fleischmajer R, et al. Scleroderma (systemic sclerosis): classification, subsets and pathogenesis. J Rheumatol 1988;15:202-5. 